\title{
Staphylococcus aureus: An Invincible Bug
}

\author{
Vikrant Negi* \\ Microbiology department, Dr Sampurnanand Medical College, India
}

Submission: July 09, 2017; Published: July 21, 2017

*Corresponding author: Vikrant Negi, Microbiology department, Dr Sampurnanand Medical College, Jodhpur, India, Email: negi.vikrant@gmail.com

\section{Abstract}

Staphylococcus aureus is a major human pathogen that causes a wide range of clinical infections. The widespread use of antibiotics resulted in the emergence of resistant strains of S. aureus. Several policies have been made by many institutes to restrict S.aureus but nothing has worked significantly.

Keywords: MRSA, Mec A; VISA; Nosocomial infection; Antibiotic resistance

\section{Introduction}

Staphylococcus aureus is a bacterium of significant importance because of its ability to cause a wide range of diseases and capacity to adapt to diverse environmental forms $[1,2]$. The organism causes infections both in human and animals such as rashes, inflammations of bones and the meninges as well as septicaemia [3]. It is now the most frequently identified drugresistant pathogen in a hospital. Penicillin and its derivatives, including methicillin have been used for the treatments of infections caused by $S$. aureus [4]. However, certain strains of $S$. aureus developed resistance known as methicillin resistant Staphylococcus aureus (MRSA). Penicillinase producing S. aureus was first reported in 1944. The ensuing years have witnessed a slow and persistent rise in penicillin-resistant $S$. aureus. By the late 1940 s, UK and USA hospitals reported $\sim 50 \%$ of $S$. aureus resistant to penicillin. A comprehensive epidemiologic study of 2000 blood isolates of S. aureus in Denmark during 1957-66 confirmed $85-90 \%$ penicillin-resistance for hospital isolates and $65-70 \%$ for community isolates [5]. In the 1950s, resistance of $S$. aureus to chloramphenicol, erythromycin, and tetracyclines emerged. Six months after the first semisynthetic penicillinase resistant penicillin, methicillin, was introduced for clinical use, three isolates of MRSA were identified in England. It gradually spread and by 1967, multidrug resistant MRSA was reported in Europe, Australia and India. By late the 1970s, MRSA isolates had spread worldwide in hospitals and communities. In USA hospitals, MRSA as a cause of nosocomial infections rose from $2.4 \%$ in 1975 to $29 \%$ in 1991 . Sharp differences in prevalence of MRSA between the various countries have been reported. In the early 1980s, gentamicin-resistant MRSA was reported from several countries. Epidemic multiresistant MRSA was reported from Australia, England and Central Europe [6].
S. aureus are colonized in anterior nares, perineum, skin or skin glands of humans and animals. The carriage rates vary from $25-50 \%$ in the general population. It is higher in diabetics, in patients with intravascular lines, in health care workers, and in drug users. Colonisation may be transient or persistent and can last for years. The efficacy of methods to reduce MRSA recurrence and transmission by decolonising carriers has not been documented. However, it may be advisable to do so in patients with recurrent MRSA infections and if there is an ongoing transmission in close contacts. S. aureus including MRSA has been isolated from various animals both infected and carriers. Transmission to man has been reported from dogs, horses, pigs and cows, as evidenced by phenotyping and genotyping of the isolates [7].

The prevalence of MRSA in India has been reported from various places. A multicentric study of MRSA surveillance was conducted in the early 1990s. 31.8\% MRSA prevalence was found in total 739 isolates of $S$. aureus. The highest incidence was found in Bangalore (47.1\%), followed by Delhi (42.5\%) and Mumbai (26.6\%) [8]. During 1992-1998 A study was conducted on 7574 strains of $S$. aureus received at the National Staphylococcal Phage Typing Centre, India. An increase in the occurrence of MRSA from $9.83 \%$ in 1992 to $45.44 \%$ in 1998 was observed [9]. In 2002, a prevalence rate of $38.56 \%$ MRSA were found in 5,039 consecutive pus samples in a tertiary care hospital in New Delhi, India [10].

MRSA is multi-resistant, being resistant to all penicilins, cephalosporins, carbapenems and betalactam and beta-lactamase inhibitor combinations. In addition, they show a variable but frequent resistance to aminoglycosides, lincosamides, 
macrolides, trimethoprim, sulfonamides and tetracyclines. A gene known as mecA gene is responsible for the resistance to methicillin which codes for penicillin-binding protein PBP 2A [11]. Lately, a new methicillin resistance mechanism gene, mecC was described in S. aureus [12]. Unlike plasmid encoded penicillinase, the methicillin resistance determinant mec, is chromosomally encoded. Some MRSA strains spread more readily than others once introduced into hospitals and are often difficult to eradicate. Such strains are also being introduced from the community to the hospitals and are posing new problems for infection control practitioners since patients coming from the communities may not be subjected to a rigorous preadmission screening used for previously hospitalised patients [13].

MRSA is the most commonly identified antibioticresistant pathogen. It is not restricted to any geographic area; it is a worldwide problem. The data from the National Nosocomial Infection Surveillance System (NNIS) and European Antimicrobial Resistance Surveillance System show that the prevalence of MRSA has been rapidly increasing. Recent surveillance data from the NNIS indicate that prevalence of MRSA in US has reached $50 \%$. The emergence of corresponding high rates of MRSA in the community is also seen. One hospitalbased study reported that up to $40 \%$ of MRSA infections in adults were acquired before admission to the hospital. MRSA is resistant to virtually all $\beta$-lactam antibiotics. Susceptibility testing now typically uses oxacillin and/or cefoxitin. $\beta$-Lactams bind to the penicillin-binding proteins (PBP) essential for cell wall biosynthesis and inhibit peptidoglycan crosslink formation, leading to bacterial cell lysis. Resistance to $\beta$-lactams in MRSA is conferred by the acquisition of a mobile genetic element, the staphylococcal cassette chromosome (SCCmec) carrying the mecA gene which encodes an altered PBP-PBP2a/PBP2' -which has reduced affinity for $\beta$-lactam antibiotics. As a result, cell wall biosynthesis in MRSA strains continues even in the presence of otherwise inhibitory levels of $\beta$-lactam antibiotics. Molecular epidemiological evidence supports that evolution of MRSA is redominantly clonal. It appears that SCCmec is transferred from coagulase-negative staphylococci (CoNS) to $S$. aureus. The epidemic hospital MRSA strains have enhanced virulence and transmissibility as they have better host cell adherence, epithelial invasiveness, and biofilm production which increases mortality, morbidity and costs [14]. Outbreaks of CA-MRSA (lineage USA 400 MW 2 strain and USA 300) have been reported in the last decade. Molecular characterization shows SCCmec type IV cassette and a combination of genes, encoding PantonValentine leucocidin (PVL) bacteviocin and enterotoxins Q and $\mathrm{K}$, with increased colonization and transmission. They are often susceptible to gentamicin, clindamycin and trimethoprimsulfamethoxazole. Insufficient clinical and epidemiologic data can't distinguish patients with CA-MRSA [15] so the clinicians face a challenge in deciding whether the therapy of CAstaphylococcal infections should include drugs traditionally used for MRSA infections [16,17]. A 15-year surveillance of staphylococcal infections in the Naval Medical Centre, San
Diego, shows that genetically, nosocomial MRSA is significantly different from that in the community [11]. CA-MRSA strains are pauci-resistant to antistapylococcal antibodies and are sensitive to clindamycin, doxycycline or trimethoprim-sulfamethoxazole.

With the worldwide emergence of MRSA in the 1980s, the use of vancomycin accelerated as the first line treatment $[18,19]$. It has been used successfully for over 50 years for the treatment of MRSA infections. Another glycopeptide, teicoplanin, has also been used widely. As a consequence of selective pressure of glycopeptides use, the first strain of $S$. aureus with reduced susceptibility to vancomycin (MIC, 8mg/litre strain MU 50) was reported from Japan in 1997 [20]. This report was quickly followed by similar ones from other parts of the world. In June 2002, a clinical isolate of vancomycin-resistant $S$. aureus (VRSA) was identified in the USA [21]. It carried van A gene which probably originated in vancomycin resistant E. faecalis, which was also isolated from the same patient. It appears MRSA acquired van A gene from E. faecalis.

There is growing evidence of vancomycin treatment failure in the management of staphylococcal infections. In a study from India, out of $783 \mathrm{~S}$. aureus strains, two were vancomycin resistant (MIC 32 and 64mg/litre) and 6 strains were vancomycin intermediate resistant (2 strains with MIC 16mg/ litre) and 2 strains with teicoplanin intermediate (MIC 16mg/ litre). One Coagulase Negative Staphylococci (CoNS) strain was resistant to vancomycin and teicoplanin (MIC $32 \mathrm{mg} / \mathrm{litre}$ ) and 2 CoNS strains were intermediate resistant to vancomycin and teicoplanin (MIC 16mg/litre). van A and van B genes were not seen in any of these isolates by PCR [22].

The strains hetero intermediately resistant to vancomycin (hVISA) have been reported in $4.3 \%$ of the 1,357 MRSA strains studied from 12 Asian countries. Though no VISA or VRSA isolates were seen in these countries [23], several published series indicate vancomycin is ineffective for the treatment of hVISA infections. Muporicin is an excellent anti staphylococcal agent for topical use and has been used to eradicate nasal carriage of MRSA in health care workers and patients, in the control of MRSA outbreaks, in the treatment of burns and superficial skin infections and as a prophylaxis before surgery. It inhibits the protein synthesis by binding specifically to isoleucyltRNA synthetase enzyme. The increased pressure of MRSA infections among patients and its carriage in health care staff has led to indiscriminate use of mupirocin which has resulted in emergence of its resistance. Plasmid-mediated high-level resistance has been reported after a prolonged and excessive use of mupirocin [24].

Once very active against MRSA, treatment failure has been observed with Fluorquinolones [25]. Fluroquinolone resistance is as high as $70-80 \%$ in Europe and the United States. Minocycline has a good activity against MRSA. New potent anti staphylococcal agents have been a development recently. Quinpristin-dalfopristin, a synergistic and bactericidal 
combination of two drugs, is an injectable semisynthetic streptogramin, active against MRSA bacteraemia, pneumonia, and skin and soft tissue infections. Linezolid is a synthetic bacteriostatic oxazolidinone active against MRSA. Linezolid has the favourable possibility of switch therapy from intravenous to oral administration. Many studies have shown excellent results with Linezolid therapy comparable to vancomycin with less adverse reactions. Daptomycin has proven effective and well tolerated for MRSA infections [26]. However, clinical failure with daptomycin therapy for $S$. aureus has been reported. Tigecycline has demonstrated antistaphylococcal activity including MRSA. Linezolid and minocycline are the only oral agents available to treat MRSA infections. Fusidic acid may offer an alternative in the treatment of staphylococcal infections given the increased incidence of MRSA. Rifampicin with other antistaphylococcal agents is effective for combination therapy of prosthesisassociated infections.

\section{Conclusion}

Drug resistance in S. aureus is of considerable importance in clinical practice. Indiscriminated use and exposure of antibiotics has led to antimicrobial resistance of $S$. aureus to penicillin, methicillin, or vancomycin. It is important to control the emergence of resistant strains in the hospital as well as in the community, regardless of their origins. Early identification MRSA can lead to early treatment. Manual practitioners can use a variety of simple and routine infection control measures to prevent infections and the transmission of MRSA between patients, clinic staff members, and the community.

\section{Conflict of Interest}

The author declares that he has no conflicts of interest.

\section{References}

1. Lowy FD (1998) Staphylococcus aureus infections. New Engl J Med 339(8): 520-532.

2. Waldvogel FA (2000) Staphylococcus aureus. In: GL Mandell, RG Douglas \& JE Bennett (Eds.), Principles and practices of infectious disease $\left(3^{\text {rd }}\right.$ edn), Churchill Livingstone, Philadelphia, Pennsylvania, USA. pp. 1754-1777.

3. Aklilu E, Zunita Z, Hassan L, Chen HC (2010) Phenotypic and genotypic characterization of methicillin-resistant Staphylococcus aureus (MRSA) isolated from dogs and cats at University Veterinary Hospital, Universiti Putra Malaysia. Trop Biomed 27(3): 483-492.

4. Rayner C, Munckhof WJ (2005) Antibiotics currently used in the treatment of infections caused by Staphylococcus aureus. Intern Med J 35 (2): 3-16.

5. Chambers HF (2001) Thechanging epidemiology of Staphylococcus aureus. Emerg Infect Dis 7: 178-182.

6. Grundmann H, Aires-de-Sousa M, Boyce J, Tiemersma E (2006) Emergence and resurgence of methicillin-resistant Staphylococcus aureus as a public health threat. Lancet 368: 874-885.

7. Juhasz-Kaszanyitzky E, Janosi S, Somogyi P, Dan A, Bloois L, et al. (2007) MRSA transmission between cows and humans. Emerg Infect Dis 13(4): 630-632.
8. Mehta AA, Rodrigues CC, Kumar RR, Rattan AA, Sri VV (1996) A pilot programme of MRSA surveillance in India. J Postgrad Med 42(1): 1-3.

9. Mehndiratta PL, Vidhani S, Mathur MD (2001) A study on Staphylococcus aureus strains submitted to a reference laboratory. Ind J Med Res 114: 90-94.

10. Mohanty S, Kapil A, Dhawan B, Das BK (2004) Bacteriological and antimicrobial susceptibility profile of staphylococcal infections from Northern India. Ind J Med Sci 58: 10-15.

11. Wielders CLC, Fluit AC, Brisse S, Verhoef J, Schmitz FJ (2002) mecA Gene Is Widely Disseminated in Staphylococcus aureus Population. J Clin Microbiol 40(11): 3970-3975.

12. Porrero MC, Valverde A, Fernández-Llario P, Díez-Guerrier A, Mateos A, et al. (2014) Staphylococcus aureus carrying mecC gene in animals and urban wastewater. Spain Emerg Infect Dis 20(5): 899-901.

13. Chugh TD (2007) Staphylococcus aureus: The modern Ghengis Khan. J Infect Developing Countries 1(2): 125-128.

14. Seybold U, Blumberg HM (2007) Reading the tea leaves or dicephering DNA microarrays: Are certain methicillinresistant Staphylocuccus aureus clones adapted to cause specific infections? Clin Infect Dis 44(4): 502-505.

15. Miller LG, Perdreau-Remington F, Bayer AS, Biep B, Tan N, et al (2007) Clinical and epidemiologic characteristics cannot distinguish community-associated methicillin-resistant Staphylococcus aureus infection from methicillin susceptible $S$ aureus infection: A prospective investigation. Clin Infect Dis 44(4): 471-482.

16. Edgeworth JD, Yadegarfar G, Pathak S, Batra R, Cockfield JD, et al. (2007) Direct evidence that MRSA strains differ in their ability to cause bacteraemia. Clin Infect Dis 44: 493-501.

17. Maree CL, Daum RS, Boyle-Vaura S, Matayoshi K, Miller LG (2007) Community-associated methicillin-resistant Staphylococcus aureus isolates causing healthcare associated infections. Emerg Infect Dis 13(3): 236-242.

18. Srinivasan A, Dick JD, Perl TM (2002) Vancomycin resistance in staphylococci. Clin Microbiol Reviews 15(3): 430-438.

19. Howden BP, Johnson P, Ward PB, Stinear TP, Davies JK (2006) Isolates with low-level vancomycin resistance associated with persistent methicillin-resistant Staphylococcus aureus bacteremia. Antimicrob Agents Chemother 50(9): 3039-3047.

20. Hiramatsu K, Hanaki H, Ino T, Yabuta K, Oguri T, Tenover FC (1997) Methicillin-resistant Staphylococcus aureus clinical strain with reduced vancomycin susceptibility. J Antimicrob Chemother 40(1): 135-136.

21. Chang S, Sievert DM, Hageman JC, Boulton ML, Tenover FC, et al. (2003) Infection with vancomycin-resistant Staphylococcus aureus containing the van A resistance gene. N Engl J Med 348(14): 1342-1347.

22. Tiwari HK, Sen MR (2006) Emergence of vancomycin resistant Staphylococcus aureus (VRSA) from a tertiary care hospital from northern part of India. BMC Infect Dis 6: 156-161.

23. Song JH, Hiramatsu K, Suh JY, Koks, ItoT, et al (2004) Emergence in Asian Countries of Staphylococcus aureus with reduced susceptibility to vancomycin. Antimicrob Agents Chemother 48(12): 4926-4928.

24. Udo EE, Mokadas EM, Jacob LE, Sanyal SC, Chugh TD (1998) Susceptibility of staphylococci isolated from a burn unit to mupirocin and other antimicrobial agents. Med Principles Pract 7: 54-60.

25. Udo EE, Al-Obaid, IA, Jacob LE, Chugh TD (1996) Molecular characterisation of epidemic ciprofloxacin and methicillin-resistant Staphylococcus aureus strains colonizing patients in an intensive care unit. J Clin Microbiol 34: 3242-3244. 
26. Marty FM, Yeh WW, Wennersten C, Venkataraman L, Alyea E, et al. (2006) Emergence of a clinical daptomycin- resistant Staphylocuccus

This work is licensed under Creative Commons Attribution 4.0 License

DOI: 10.19080/CTBEB.2017.05.555672 aureus isolate during treatment of methicillin-resistant Staphylococcus aureus osteomyelitis. J Clin Microbiol 44(2): 595-597.

\section{Your next submission with Juniper Publishers will reach you the below assets}

- Quality Editorial service

- Swift Peer Review

- Reprints availability

- E-prints Service

- Manuscript Podcast for convenient understanding

- Global attainment for your research

- Manuscript accessibility in different formats

( Pdf, E-pub, Full Text, Audio)

- Unceasing customer service

Track the below URL for one-step submission https://juniperpublishers.com/online-submission.php 